\title{
O Modelo de Black - Scholes e suas Implicações para os Mercados de Futuros e de Opções
}

\author{
Bruno F. C. da Silva* José Lucas P. Luiz Fábio S. de Souza \\ Departamento de Ciências Exatas, DCEX-UFVJM, \\ Universidade Federal dos Vales do Jequitinhonha e Mucuri, \\ 39803-371, Teófilo Otoni, MG \\ E-mail: brunobfcs@ymail.com, lucasvt09@hotmail.com, fabio.souza@ufvjm.edu.br
}

\begin{abstract}
Resumo- O modelo de Black-Scholes permite a um investidor analisar criteriosamente se o preço de um ativo financeiro num processo de compra e venda é justo. Tem-se por objetivo fazer uma construção matemática deste modelo, bem como demonstrar sua resolução no tocante à determinação de possíveis soluções.
\end{abstract}

Palavras - chave: Black-Scholes, Opções Europeias, Ativos.

\section{Introdução}

Em 1973 os economistas Fischer Black e Myron Scholes apresentaram no artigo "The Princing of Options and Corporate Liabilities" a fórmula de Black-Scholes, conforme [1], para descrever o comportamento de opções europeias. O modelo de Black-Scholes tornou-se um dos modelos mais utilizados para a precificação de ativos financeiros, como pode ser visto em [2]. Este modelo permite a um investidor analisar criteriosamente se o preço de um ativo financeiro num processo de compra e venda é justo, com uma pequena margem de erro. A partir daí, surge então a necessidade de analisar este modelo, que é utilizado até hoje em processos envolvendo grandes transações.

\section{Metodologia}

Inicialmente, foi realizada uma revisão bibliográfica dos principais artigos e livros relacionados ao assunto, bem como artigos e trabalhos sobre a Bolsa de Mercadorias e Futuros, a fim de coletar dados a respeito da precificação de opções. Após este estudo, desenvolvemos o estudo da teoria referente ao modelo de Black-Scholes, tendo início com o estudo de equações diferenciais estocásticas e, posteriormente, passando à construção do modelo propriamente dito. Uma vez vista a construção do modelo, foram realizados estudos e análises das possíveis soluções da equação de Black-Scholes, bem como estudamos também as análises da precificação de opções, objetivando futuras previsões. Por fim, tendo em mãos toda a teoria de mercado e a construção e resolução do modelo proposto por Black-Scholes apresentamos uma simulação de como esse modelo é aplicado com base em dados reais.

\section{Apresentação do Modelo}

O modelo de Black-Scholes modela o preço $C$ de uma opção europeia, em função do tempo $t$ e do valor $S$ do ativo, conforme a equação abaixo,

\footnotetext{
* Bolsista de Iniciação Científica PIBIC/FAPEMIG
} 


$$
\frac{\partial C}{\partial t}(t, S)+\frac{1}{2} \sigma^{2} S^{2} \frac{\partial^{2} C}{\partial S^{2}}(t, S)+r S \frac{\partial C}{\partial S}(t, S)-r C(t, S)=0
$$

permitindo a um investidor obter o melhor preço possível de um derivativo financeiro.

A solução deste modelo, para a obtenção do valor de uma opção de compra, pode ser obtida com procedimentos semelhantes à solução da Equação do Calor, através do método de separação de variáveis. Fazendo algumas mudanças de variáveis transforma-se a equação de Black-Scholes em uma equação do calor, onde é possível encontrar uma expressão analítica que é dada por;

$$
C(t, S)=S N\left(\frac{\log \left(\frac{S}{E}\right)+\left(r+\frac{\sigma^{2}}{2}\right)(T-t)}{\sigma \sqrt{(T-t)}}\right)-e^{-r(T-t)} E N\left(\frac{\log \left(\frac{S}{E}\right)+\left(r-\frac{\sigma^{2}}{2}\right)(T-t)}{\sigma \sqrt{(T-t)}}\right)
$$

seguindo uma distribuição gaussiana. O modelo de Black-Scholes possui a hipótese de que os preços seguem um processo de difusão browniana ou, mais precisamente, um processo de Wiener, como pode ser visto em [2]. O parâmetro de qualquer processo de difusão é desempenhado por uma constante chamada, muitas vezes, de coeficiente de difusibilidade. No modelo de Black-Scholes, o coeficiente de difusibilidade é o $\sigma^{2}$. Se recorremos à função de distribuição (cumulativa) de uma lei de probabilidade normal de média 0 e desvio padrão 1 encontramos a solução de $C(t, S)$, sendo $S$ nossa variável aleatória.

Com isso, é possível obter soluções para o modelo com base em dados reais negociados na bolsa de valores.

\section{Resultados}

Em nossas análises bibliográficas sentimos a carência de várias demonstrações usadas como ferramenta na construção teórica e metodológica do modelo de Black - Scholes, como por exemplo, a construção e aplicação do Lema de Itô, que pode ser visto em [3]. Outro resultado é obtido do teorema da continuidade de Kolmogorov, que garante a existência de uma versão contínua do Movimento Browniano, como pode ser visto em [3]. Um resultado forte é a resolução analítica da equação de Black - Scholes, que pode ser entendida como uma equação de convecção-difusão, através da integral de Poisson, que pode ser visto em [2].

\section{Conclusão}

A teoria de Black-Scholes para o apreçamento de um ativo é de extrema importância para o mercado financeiro. Em mercados financeiros podem ocorrer eventos que influenciam nos preços de uma opção. Assim uma análise matemática dessa teoria nos ajuda a compreender melhor situações reais em economia e finanças, nos ajudando a tomar melhores decisões quando lidamos com teoria de mercados.

\section{Referências}

[1] F. Black, M. Scholes, "The Pricing of Options and Corporate Liabilities", Journal of Political Economy 81, 637-654, 1973.

[2] E. M. Bonotto, “A equação de Black-Scholes com Ação Impulsiva”, USP-São Carlos, Maio/2008, Tese de Doutorado, Instituto de Ciências Matemáticas, Universidade de São Paulo.

[3] B. Oksendal, "Stochastic Differential Equations", Springer Verlag, 1998. 